\title{
Identidades en tránsito. Migración y reapropiación del espacio en el sur latinoamericano
}

\section{Identities in transit. Migration and reappropriation of the space in the Latin American south}

\author{
Correa, Verónica, Idenilso Bortolotto y Alain Musset \\ (eds.) (2013), GEOGRAFÍA DE LA ESPERA. MIGRAR, HABITAR Y TRABAJAR \\ EN LA CIUDAD DE SANTIAGO, CHILE. 1990-2012. \\ Fundación Scalabrini-Ugbar Editores, Santiago de Chile, \\ 349 PP. ISBN 978-956-9171-16-1
}

El libro es una compilación de artículos que expresan las distintas problemáticas que presenta el desplazamiento territorial de población del sur de América Latina a la ciudad de Santiago de Chile; tiene como objeto establecer sus dimensiones, incluir sus estatutos jurídicos, sus articulaciones con el espacio circundante, sus temporalidades específicas, así como la variedad de los juegos económicos y sociales que se despliegan en su marco, es resultado de un reto que se ha puesto un grupo internacional de historiadores, geógrafos, sociólogos, antropólogos, filósofos y literatos reunidos en el equipo de TERRIAT (siglas derivadas de Territorios de la Espera, Territoires de l'Attente, en francés) (p. 27).

El texto está integrado por una introducción y tres capítulos generales. El primero de ellos tiene cuatro sub apartados en los que se manifiesta el impacto político de la migración del sur al mismo sur. El segundo de los apartados cuenta con dos reflexiones que centran su eje de discusión en las dinámicas culturales influenciadas por aspectos como la feminización de la migración y la religiosidad.

En la tercera parte se encuentran tres análisis sobre los cambios que se han generado en el espacio urbano santiaguense, a partir de la migración sudamericana hacia la capital de Chile. Cada artículo tiene sus propias reflexiones finales y sus fuentes bibliográficas.

En el prefacio se expresa la importancia del libro debida a las aportaciones, resultado de la reflexión de los fenómenos que han aparecido, recientemente, a partir de la migración latinoamericana, en la ciudad de Santiago de Chile. Se hace énfasis en las miradas microsociales de 
dichos fenómenos resguardando las dimensiones de su impacto global y continental.

La introducción revela la intensión principal por la cual se hace la compilación de nueve artículos que brindan luces en la reflexión de los fenómenos migratorios en la capital chilena. El texto enfatiza el cambio genérico de la dinámica migrante que se presentó desde las últimas décadas, pues es evidente la feminización de la población migrante y las consecuencias sociales que ello produce, tanto en los lugares de origen como en los de llegada, en las formas de apropiación del espacio y en las construcciones identitarias dentro de ellos.

El libro, en palabras de los editores, se ubica "en la encrucijada entre geografía y sociología [que] conforma entonces una geografía social donde la psicología de la espera impacta la manera en que los hombres y las mujeres en proceso migratorio se apropian un espacio en la medida (y a la medida) de sus capacidades tanto económicas como sociales y culturales" (p. 18). Los ítems claves de las reflexiones son la migración, el habitar y el trabajo.

Los instrumentos metodológicos se basan en fuentes estadísticas del Instituto Católico Chileno de Migración (Incami) y el Centro Integrado de Atención al Migrante (Ciami) de la Fundación Scalabrini, así como en entrevistas a migrantes.

La primera parte se denomina "Geopolítica y movilidad"; el artículo que abre el apartado lleva por nombre "Efectos de la ratificación de los tratados internacionales de derechos humanos y acuerdos regionales en la legislación migratoria chilena", la autora es Patricia Donaire, maestra en derecho de las migraciones y cooperación internacional por la Universidad de Bérgamo (Italia) y colaboradora en Incami.

Donaire señala que a partir de los noventa comienza un nuevo escenario migratorio chileno y que un factor como el económico hace a este país un atractivo destino para migrar; las tasas de movilidad internacional propician condiciones de vida que obligan a los gobiernos a revisar las leyes que regulan el ingresó al país, por ejemplo el decreto ley número 1.074, Ley de Extranjería y su Reglamento, que entraron en vigor en 1975 y 1984, respectivamente. Esta normativa se creó durante el periodo de la dictadura militar, la cual, dado el contexto histórico y político, tuvo como principio rector la seguridad nacional.

La autora presenta una reseña histórica de la legislación migratoria chilena desde la dictadura, donde se firman las leyes mencionadas, hasta los tiempos de la democracia, y compara el estatus legal en cuanto al ingreso de las personas al país con el marco jurídico internacional y las ratificaciones que Chile ha hecho de éstos, asimismo, menciona los procesos regionales sobre el tema migratorio y enfatiza en los logros del 
Tratado Constitutivo del Unasur, que busca la consolidación de una identidad suramericana por un lado y, por el otro, la cooperación mutua en materia migratoria entre los países que lo conforman.

Afirma que en términos generales el marco jurídico chileno, con respecto al extranjero, está conformado por normatividades nacionales e internacionales, globales y locales que aseguran los derechos humanos (condiciones de vida dignas) de quienes se desplazan temporal o de manera permanente, voluntariamente o por exilio, dentro del territorio suramericano y de quienes arriban a Santiago de Chile.

Sin embargo, el problema radica en que en la práctica esto no se ve reflejado, el migrante sigue siendo invisible para instituciones que debieran salvaguardar la integridad, es el caso de las sanitarias, las familiares o las jurídicas.

"Una aproximación descriptiva y sociodemográfica de las mujeres inmigrantes en Santiago de Chile, desde el registro de Ciami”, de Jorge Martínez, geógrafo, demógrafo e investigador del Centro Latinoamericano y Caribeño de Demografía (Celade) en Santiago de Chile, y de Magdalena Soffia, socióloga consultora del Celade, es el segundo artículo del libro. En este texto se brindan datos que, como mencionan los autores, sirven como instrumento que derivó de un gran número de casos que evidencian los cambios en el proceso migratorio de mujeres sudamericanas en Santiago.

Los autores señalan que la información arrojada por los registros del Ciami indica que las 25 mujeres sondeadas se asumieron como latinoamericanas o caribeñas y no así como peruanas, nacionalidad de $90 \%$ de ellas. La causa de este proceso identitario es que ha habido cambios radicales en la composición de la inmigración a Chile en la última década; dicha hipótesis la comprueban las encuestas de Casen, ${ }^{1}$ lo que obliga a repensar los cambios en el perfil de los inmigrantes.

Uno de los cambios más evidente es la feminización de la inmigración desde la década del 2000. La principal causa de movilidad es la búsqueda de trabajo, pues es la inserción laboral la principal necesidad de estas mujeres al ingresar al país. El rango de edad de la población migrante va de los 15 a los 19 años, rango de población económicamente activa, en su mayoría mujeres separadas, es decir, jefas de familia que deben cubrir las necesidades de quienes pertenecen a su núcleo familiar y resolver la crianza de los hijos y el cuidado de los padres, así como de quienes están bajo su responsabilidad. En su mayoría viven solas en Chile y sus familiares, principalmente sus hijos, se encuentran en sus países de origen.

\footnotetext{
${ }^{1}$ Encuestas disponible en: http://observatorio.ministeriodesarrollosocial.gob.cl/casen_obj.php
} 
Lo expuesto en este artículo evidencia la urgencia de implicar en la normatividad de migración chilena la perspectiva de género, que permita a las mujeres migrantes acceder a condiciones mínimas de seguridad, principalmente laborales, ya que de ellas se derivan otros factores. Finalmente, los datos presentados formulan preguntas que abren vetas a investigaciones sobre el tema y dan seguimientos acertados a los problemas de la migración en Chile.

En el último apartado de la primera parte Florencia Jensen, socióloga e investigadora-tesista del Instituto de Investigaciones Gino Germani, y profesora de la Universidad de Chile, titula a su artículo "Atravesar la frontera: la huella perpetua en la experiencia migratoria", y centra la discusión del fenómeno de migración en Chile en el tránsito, en el antes y el después de la salida y la llegada.

El artículo de Jensen propone abordar la migración desde el espacio intermedio, en la frontera. Afirma la autora que lo sociopolítico establece límites geográficos, políticos, administrativos y simbólicos. Es decir, que el cruce define las condiciones en las que se desarrollará el migrante.

Florencia Jensen brinda un marco histórico y general de la migración reciente en Chile, las gráficas que presenta dan cuenta del crecimiento de la tasa de inmigración en el país a partir de la década de los noventa; Perú es el país de origen de casi $30 \%$ de la población migrante.

Expone que "la frontera y la nación han demostrado continuar siendo categorías de identificación de los Estados y de los sujetos, donde las imágenes y representaciones contenidas en ellas permean las relaciones que se establecen" (p. 108), por lo tanto, señala que la frontera se convierte en una herramienta política que va adecuando el proceso migratorio a los intereses políticos y económicos. Para dar claridad a tal aseveración reseña el concepto en su dimensión política y cultural.

Hace énfasis en la relación entre la frontera y el Estado, para puntualizar en la función de ésta en el ejercicio del poder estatal, generándose preguntas como ¿qué rol desempeña el Estado nacional?, ¿se puede regular un proceso global, como es la migración internacional, con políticas estrictamente nacionales?, o ¿̇resulta más apropiada la aplicación de políticas migratorias transnacionales para la gobernabilidad y gobernanza de la migración? Dada la nueva coyuntura internacional, ¿̨resulta insuficiente afirmar la soberanía del Estado en la formulación de la política migratoria? A estos cuestionamientos intenta dar respuesta a lo largo del texto.

La autora también reflexiona sobre los límites territoriales desde la experiencia subjetiva del migrante, a partir de testimonios de migrantes organizados en tres ejes: la salida, el cruce y el impacto en la vida del migrante al llegar. En el primero se señala que 
las migrantes en general apelan a las redes migratorias y los lazos sociales representados por el parentesco, la amistad o sólo la nacionalidad, que ayudan y colaboran a sortear las dificultades que se van presentando en la vida como migrante. Así, estas redes se tornan más importantes e indispensables cuanto más compleja, vulnerable y precaria es la situación del migrante (p. 127).

En el segundo se encuentra que "Las migrantes que se enfrentan a situaciones complejas, son rechazadas, deportadas, e insisten una y otra vez, hasta que logran ingresar al país y concretar el proyecto migratorio, y para ello apelan, como se observa en el relato, al ingenio, la inventiva y solidaridad" (p. 130). Y en el tercer eje se menciona que "el impacto que tiene la frontera en la vida como migrante marca en última instancia la percepción de ser o no un sujeto de derechos" (p. 132).

El artículo propone reflexionar más sobre los imaginarios que se construyen alrededor de la frontera y cómo éstos impactan las condiciones de vida del migrante en el lugar de llegada, de tal manera que la experiencia migratoria se valore desde otras aristas como en la huella que deja la migración en la subjetividad del migrante, así como las implicaciones de ello.

El último de los artículos de este primer capítulo es "Novedad migratoria: Refugiados colombianos en Chile", de Carlos Mauricio Ortegón, analista social del Centro de Estudios Internacionales de la Pontificia Universidad Católica de Chile.

El autor tiende su eje de análisis sobre la migración obligada, aquélla que se da a partir de la solicitud de asilo político. El objetivo de este artículo es el de visibilizar la existencia de población refugiada en Chile, tomándose en cuenta las particularidades del caso colombiano.

El primer aporte es una distinción entre los diversos perfiles migratorios, puntualizando en la migración de los refugiados, es decir, la asociada a "un tipo específico de migración forzada, motivada por conflictos que afectan a las comunidades de origen que ponen en riesgo la vida e integridad de las personas" (p. 143). Deja en claro la diferencia entre migración forzada y migración tradicional.

Dentro de la migración forzada que llega a Chile, $56 \%$ de los casos corresponde a población de origen colombiano, que con 884 personas se convierte en el país con mayor número de refugiados en este país, como resultado del conflicto armado en Colombia. Es a partir del 2005 que se ve un crecimiento importante en esta tasa.

Existen dos tipos de refugiados, afirma Ortegón, los refugiados agudos que ocurre en el momento de la agresión y los refugiados anticipatorios, quienes al sentir el peligro en Colombia toman la decisión de realizar un desplazamiento. El desplazamiento migratorio no se da de un punto $\mathrm{A}$ hacia uno B, es decir, no es directo de alguna ciudad de Colombia hacia Chile, sino que los entrevistados señalan que primero se dio un despla- 
zamiento dentro de Colombia, luego se migró a los países limítrofes como Ecuador o Venezuela, para terminar el desplazamiento en Chile. Los entrevistados dicen haber hecho uso de redes familiares para lograr esta larga travesía hasta arribar al país receptor.

El migrante refugiado no cuenta con apoyo institucional, por lo que la elección del país receptor es a partir de

las oportunidades de información que logran adquirir por sus pares tanto en el país de origen como en el proceso de ruta (huida). Además, la calidad de su desplazamiento depende de los medios económicos con los que cuenta, lo que obliga, en su mayoría, a hacer uso de medios de transporte terrestres y la necesidad de construir redes esporádicas que les permitan reafirmar su información o generar una nueva. Esta última categoría es, por lo tanto, el grupo de población más vulnerable (p. 169).

Por ello es que el refugiado se ha visto obligado a recurrir a vínculos de solidaridad con sus pares, quienes comparten su eventualidad como migrantes, lo que dificulta la distinción de los tipos de migración en Chile.

La migración de refugiados en Chile es una problemática que tiene que ser atendida, primero se debe visibilizar y después brindarles información del refugio al migrante, mediante políticas.

El capítulo II, "Cultura y movilidad", comienza con el texto: "Dinámicas globales y de género en la migración de las mujeres asentadas en la ciudad de Santiago", de Sara Salvatori, candidata a doctora por la Universidad de Sevilla.

Salvatori centra su análisis cuantitativo en el trabajo de las mujeres migrantes que llegan a la capital de Chile. Afirma que la feminización de la migración se presenta en todo el mundo, por lo que el objetivo del documento es "analizar las dinámicas que rigen el desplazamiento de las mujeres latinoamericanas hacia Chile y su inserción en el mercado de trabajo, enfocándonos en el papel de las relaciones de género dentro del sistema de producción capitalista y los efectos que este proceso adquiere a nivel global en la formación de circuitos altamente feminizados" (p. 180).

Para el análisis de la feminización de la migración, la autora toma en cuenta dos instrumentos: el informe de la ocDE y el trabajo de Pajares. Ambos dan muestra de que la crisis económica ha impactado en el género de la población migrante, convirtiendo a este elemento en uno de los estructuradores de la dinámica económica, política y social. Algunos de estos cambios son que los más afectados son los varones al tener que emplearse en un mercado laboral particularmente dañado por la crisis y las mujeres se ven obligadas a migrar y tomar el papel de proveedoras y sustentadoras de sus núcleos familiares. 
Otro factor que lleva a las mujeres a migrar es la feminización de la pobreza

El desarrollo de estrategias de resistencia ante el proceso de feminización de la pobreza ha contribuido a la formación de una feminización de la supervivencia, que se lleva a cabo a partir del aumento de la migración internacional de las mujeres (feminización de las corrientes migratorias) y su entrada masiva en el mercado laboral (feminización de la fuerza de trabajo), ya sea en el país de origen o en el de asentamiento (p. 187).

Si bien se dice que el flujo migratorio es hacia ciudades globales, y Santiago no es considerada como tal, se ha convertido en una ciudad de migrantes indígenas originarias de Perú y Bolivia, ya que estas mujeres hacen labores domésticas y de cuidado personal. "Dentro de estas dinámicas, las migraciones femeninas perpetúan y fortalecen el sistema capitalista y el patriarcal, puesto que la entrada de las mujeres autóctonas en el mercado laboral deja espacio para que otras mujeres se ocupen de realizar el trabajo doméstico o de cuidar de las personas dependientes" (p. 193).

La reflexión que deja la autora es que la inserción laboral del migrante en Chile está marcada por la etnia y el género, lo que fomenta las dinámicas de segregación y jerarquización en el acceso de los migrantes al mercado laboral.

"Fe y catolicismo popular de los migrantes latinoamericanos en Santiago de Chile. Apuntes para la comprensión de la fe itinerante desde la perspectiva del Incami en la Parroquia Personal para los Migrantes Latinoamericanos de Santiago" es el sexto artículo del libro y el segundo del capítulo II. Escrito por José Delio Cubides, candidato a maestro en ética social y desarrollo humano de la Universidad Alberto Hurtado de Santiago, y secretario ejecutivo del Instituto Católico Chileno de Migración (Incami), y por Idenilso Bortolotto, editor del libro. Este artículo es una reflexión cualitativa que parte del testimonio de los migrantes.

Se afirma que muchos viajan sin el conocimiento o la información precisa de los documentos que requerirán o las necesidades a las cuales deben enfrentarse, por lo que algunas de las experiencias del migrante en el país receptor no son tan agradables como éstos las imaginaban. Los cambios en las subjetividades después de acontecimientos desagradables: robos, vejaciones, violaciones a sus derechos humanos, etcétera hacen que el migrante busque espacios de reconstrucción de sí mismo y de apoyo.

Es así como

la religión y la práctica de la piedad popular ofrecen condiciones y herramientas para superar o atenuar situaciones límite del ser humano y particularmente de la migración, como la soledad, la angustia, la incerteza, la preocupación, la ansiedad, 
la espera, o más difíciles, como la inminencia del desastre, o de la muerte, etc. Así también, ella permite hacer una lectura que contrapone raíces o tradiciones distintas (p. 215).

El objetivo del artículo es reflexionar en torno a las manifestaciones de fe desde el catolicismo popular que acompaña la realidad de los migrantes, la cual incide en la experiencia migratoria en Santiago de Chile.

Se dice que catolicismo popular es la religión presente en América Latina, derivada de la tradición popular de la religiosidad católica; esta Iglesia ofrece una posibilidad de construcción de redes que permiten al migrante la supervivencia en países receptores, desconocidos para ellos.

Y es que "la Parroquia latinoamericana ofrece la posibilidad de que los migrantes se organicen por colectividades en torno a líderes que articulan los distintos miembros" (p. 233). Es decir, si "la religión, en su práctica popular, es, como tal, mediación social de participación y de inserción del migrante a la nueva sociedad" (p. 245), el migrante encuentra en ella un espacio de identidad y pertenencia, así como la posibilidad de vincularse a una colectividad de la sociedad del país que lo recibe.

La tercera parte del libro, "Ciudad y desplazamiento", comienza con el artículo: "Urbanidades en pugna: usos y memorias del espacio en la migración peruana en Santiago de Chile", de Alejandro Garcés, doctor en antropología social por la Universidad Autónoma de Madrid, e investigador del Instituto de Investigaciones Arqueológicas y Museo (IIAM) de la Universidad Católica del Norte.

En este apartado se abordan cualitativamente algunas de las prácticas de apropiación de los migrantes respecto a los espacios urbanos, se menciona el tipo de relaciones sociales que los caracterizan por ser lugares en donde los migrantes se asientan. Se hace una revisión teórica de lo que es considerado el espacio público, lo urbano y la urbanidad, la ciudad y la calle.

En un segundo momento, el autor nos presenta una reflexión acerca de la territorialidad, como evidencia de la actuación conjunta de diversas formas o lógicas de organización social que conviven en un mismo espacio y que se problematizan en Santiago cuando emergen un conjunto de nuevas prácticas que se desarrollan en las centralidades migrantes, conflictuando las relaciones entre individuos, grupos e instituciones.

En este caso las prácticas de los migrantes peruanos van generando nuevos imaginarios de la peruanidad en un país y una ciudad ajenos, que modifican las prácticas dentro del espacio público en Santiago de Chile.

$Y$ es que el peruano migrante ocupa el espacio público como un lugar para reproducir su memoria, su imaginario, su peruanidad. Lo expresado en los relatos de los migrantes habla de que 
la diversidad de posiciones que representan cada uno, articulan precisamente la memoria de una práctica cultural que hace referencia a la necesidad de contar con un lugar de encuentro, cuestión que se fundaría en la existencia de una costumbre de los peruanos migrantes, como una suerte de condición de la peruanidad migrante, ya sea que se trate de una migración transnacional o de una migración interna de carácter rural-urbano (p. 267).

En síntesis, el artículo de Garcés pone a discusión la concentración del migrante peruano en el espacio público de Santiago de Chile, da luces de las modificaciones de éste a partir de la reproducción de la memoria y la cultura peruana, y afirma que el espacio público se ha convertido en esta ciudad en espacio determinado por un conjunto de fuerzas económicas y urbanísticas al servicio de un proyecto modernizador que renueva la urbanidad de esta ciudad, según sus palabras.

Menciona el uso comercial de la calle definiéndola como espacio de la economía étnica y espacio urbano de la migración peruana para la reproducción del colectivo migrante, lo que genera un conflicto entre identidades chilenas y peruanas dando lugar a una disputa por los usos legítimos del espacio.

El segundo artículo del tercer capítulo se titula: "Geografía de la crisis del cuidado en Santiago: una aproximación centrada en la demanda de mano de obra extranjera”, de la autoría de Verónica Correa y Dominique Vidal, profesor de sociología en la Universidad París, quienes abren la discusión haciendo énfasis en la llamada crisis del cuidado doméstico.

Los autores mencionan que las variaciones económicas y demográficas de la última década en Chile han dejado como consecuencia cambios en la inserción laboral de las mujeres peruanas en este país, por lo que el capítulo tiene como objetivo "estudiar la demanda del cuidado doméstico en la Región Metropolitana, específicamente las personas que, entre el año 2004 hasta el 2011, han acudido a Ciami en búsqueda de mano de obra extranjera” (p. 287-288).

La variable dependiente del análisis es la demanda del cuidado doméstico y las variables independientes son: a) el patrón de localización de los empleadores, su composición socioeconómica, la distribución de género y oficios, así como sus preferencias en cuanto a la nacionalidad y condición de los contratados; b) el perfil del grupo empleador, desde una perspectiva socioespacial. Las bases de datos utilizadas son las del Ciami de mayo de 2004 a mayo de 2011.

Entre la información más relevante de la descripción estadística está que los empleadores del trabajo doméstico enfocado en el cuidado se sitúa dentro de las comunas de nivel socioeconómicamente medio alto y, principalmente, alto, por ejemplo, Los Condes y La Provincia. 
Se afirma que " $85 \%$ de las personas que llegan a Ciami en búsqueda de un trabajador del cuidado son mujeres, contra $15 \%$ que son hombres, porcentaje que, sin ser importante, muestra también la participación masculina en un ámbito que todavía es asunto de mujeres" (p. 296). También las estadísticas indican que el casi 50\% de los varones que solicitan cuidados son profesionistas, intelectuales y científicos con un nivel socioeconómico alto.

La migración femenina empleada en el trabajo doméstico genera un fenómeno denominado cadenas globales de cuidado, concepto desarrollado por la socióloga Arlie Hochschild. Cuya premisa es que, las migrantes que realizan la labor de cuidado de hijos y hogares dejan en sus países de origen a sus propios hijos al cuidado de familiares, creando eslabones de trabajo de cuidado.

Las migrantes están llenando el vacío en la oferta de servicio doméstico a puertas adentro en el país, por lo que el artículo hace un llamado de atención hacia este tipo de migración, cuyo origen está en la etapa colonial, pero cuya vigencia es evidente. Se afirma que el empleo doméstico está lejos de desaparecer y que la característica actual es que lo ejerce población migrante. En Chile se realiza por peruanas, en su mayoría, indígenas.

Dicha dinámica social es una prioridad en la atención a la problemática de migración en este país, tanto por las condiciones de las migrantes y sus derechos laborales como por las cadenas de cuidado que están implícitas y que obligan a los países originarios y a los receptores a centrar la mirada en esta dinámica laboral y sus consecuencias.

El último de los artículos que constituyen el libro: "Una dimensión espacio-temporal de la espera: el patrón residencial de las inmigrantes latinoamericanas en la última década en Santiago de Chile”, de la autoría de Verónica Correa, Jean-Claude Raynal, geógrafo e ingeniero de estudios en representación de datos de referencia espacial en el CNRS-IMBE y Alain Musset; tiene como eje rector de discusión la dimensión espacio-temporal en el análisis de los datos para la comprensión de la trayectoria del proceso migratorio en Chile. En esta investigación se toca el tema de las transformaciones en la dinámica laboral de las mujeres migrantes en Chile, la ausencia de las madres de sus hogares en sus países de origen y la preferencia de éstas por laborar puerta adentro en los hogares donde fueron empleadas.

Se afirma en este apartado que incluso hay mujeres que logran adquirir su Rol Único Tributario (RUT) y con ello el acceso a algunos beneficios sociales como la educación escolar y la salud pública a los dos años de estancia en Chile. Sin embargo, no se ha generalizado este recorrido migratorio ya que las empleadas a puerta de entrada, que son las que 
trabajan por horarios, habitan en las zonas céntricas de Santiago en condiciones precarias debido al alto valor del suelo que hace que las rentas tengan costos elevados, razón por la cual las migrantes optan por la renta de cuartos sumamente pequeños, o bien, por el allegamiento, con hacinamientos que provocan enfermedades físicas y psicológicas del grupo, afirman los autores.

El artículo indaga sobre los elementos implicados en el comportamiento residencial de las extranjeras que se inscriben en Ciami y que permanecen, a pesar de lo complicado de la estadía, en zona céntricas de Santiago.

Mediante un análisis georreferencial con el que se construye una cartografía de la distribución espacial de las migrantes en la ciudad, se afirma que la decisión por la zona de residencia es consecuencia del "conjunto de prácticas individuales y colectivas, localizadas y fuertemente instrumentalizadas y que juegan un rol organizador en la construcción y manufacturación del presente" (p. 345), constituyendo a su vez los elementos de asimilación o integración de los grupos de migrantes en Santiago de Chile.

En este sentido, en palabras de los autores, podría decirse que

el inmigrante sacrifica su presente, bajo la expectativa de que constituye un periodo extraordinario y finito, que prontamente tendrá término. Este momento extraordinario vivido por el inmigrante, trae consigo una trasformación en la concepción del tiempo, y nuevas configuraciones que se expresan en ámbitos como son sus condiciones de habitabilidad y su localización residencial en la ciudad (p. 345).

Cierra el texto con una serie de mapas que dan muestra de la confirmación de la hipótesis planteada.

En general, el libro brinda diversas miradas sobre la situación actual de la migración en Chile. Hace un llamado a centrar la atención sobre la feminización indígena de la migración en este país y da cuenta de algunos de los problemas que ella trae consigo, asimismo, permite al lector reflexionar acerca de las consecuencias que se pudiesen generar a mediano y largo plazo, así como de los conflictos experimentados por los y las migrantes en la actualidad.

El texto invita a replantear conceptos como el de espacio público, urbanización, identidad y territorio, entre otros. Deja entrever la reproducción de patrones de género y la exclusión del sujeto en espacios considerados ajenos. Coloca en la discusión la emergencia de normatividades que resguarden los derechos básicos del migrante, permite a las instituciones una lectura más clara de la situación de la migración en Santiago de Chile y proporciona luces a las instituciones de los países de origen de estos migrantes para que puedan contribuir a la solución de las proble- 
máticas a las que se enfrenta su población. Es un gran aporte a los estudios territoriales y urbano sociales en América Latina.

Recibida: 13 de junio de 2013. Aceptada: 6 de noviembre de 2013.

Ana Lilia Salazar Zarco Instituto Superior Intercultural Ayuuk (ISIA)

Correo-e: zarcoal@gmail.com

Ana Lilia Salazar Zarco. Maestra en estudios latinoamericanos por la Universidad Nacional Autónoma de México, licenciada en sociología por la Universidad Autónoma del Estado de México, de septiembre a diciembre de 2013 fue coordinadora administrativa del proyecto Redes ciudadanas de actuación en detección, apoyo y referencia en situación de violencia contra las mujeres del ITA, Transformación Innovación Comunicación Potencial y Desarrollo s. C., y la Universidad Autónoma Metropolitana unidad Xochimilco; asistente de investigación en UAEM en la Red Nacional de Investigadores de la Democracia en México, Сісsун, en 2012, y en el Diagnóstico integral sobre la situación actual del envejecimiento en el Estado de México, en el CiaEap, de 2008 a 2009. Docente en nivel superior. 